\title{
USING IPTV SERVICES IN DISTANCE LEARNING SYSTEMS
}

\author{
Stanimir M. Sadinov, Jordan H. Kanev, Iskren O. Kandov \\ Technical University of Gabrovo
}

\begin{abstract}
:
This paper shows development of Internet Protocol Television (IPTV) services and integration in existing distance learning platform for educational purposes. IPTV offers new approach in teaching and delivering of study materials to students. Students can watch digital course content on various mobile or portable devices like smartphones and tablets over the Internet. The Distance learning platform includes three IPTV services (live video stream, video on demand, Audio Q\&A). The result of the Distance learning system and IPTV Distance learning system evaluation found that new IPTV had a higher user satisfaction than old system. Furthermore, an IPTV service creates a good learning experience for the students. This paper provides guidelines how to use IPTV services for education.
\end{abstract}

\author{
Key words: \\ IPTV, \\ Distance Learning, \\ educational innovation, \\ Video on Demand, \\ Personal Video Recorder.
}

\section{INTRODUCTION}

Distance learning systems are very popular lately. There are few different platforms like Learning Management Systems (LMS) and Course Management Systems (CMS) with main goal to offer online training courses. Our distance learning system is based on one of the most commonly used in education institutions in the world LMS system called Moodle [1]. Moodle is a GPL opensource learning platform with modular construction and allows plugins for adding new functionality and features.

Main features include:

- Enrollment and registration

- Assignment submission

- Discussion forum

- Files download

- Grading

- Moodle instant messages

- Online quiz

- Activities

- Reports

These features are both plugins and PHP code written by our team to make this system usable by students. Students are not only graded but also tracked how much time they spend logged in and if there is inactivity more than 1 hour they are logged out and no working time is added to their gradebook.

Lectures and study materials are presented in PDF format for students to download or read directly from distance learning system. Activities and exams are scheduled for certain date and time and they appear in the system only for short period of time.
Fig. 1 shows login screen of distance learning system. Every student must obtain username and password to access the system. There cannot be two students with the same username logged in in the system and working online at the same time. If the same user is logged in second time, the first user is automatically disconnected and time spend online for this user is not added to total time spend online.

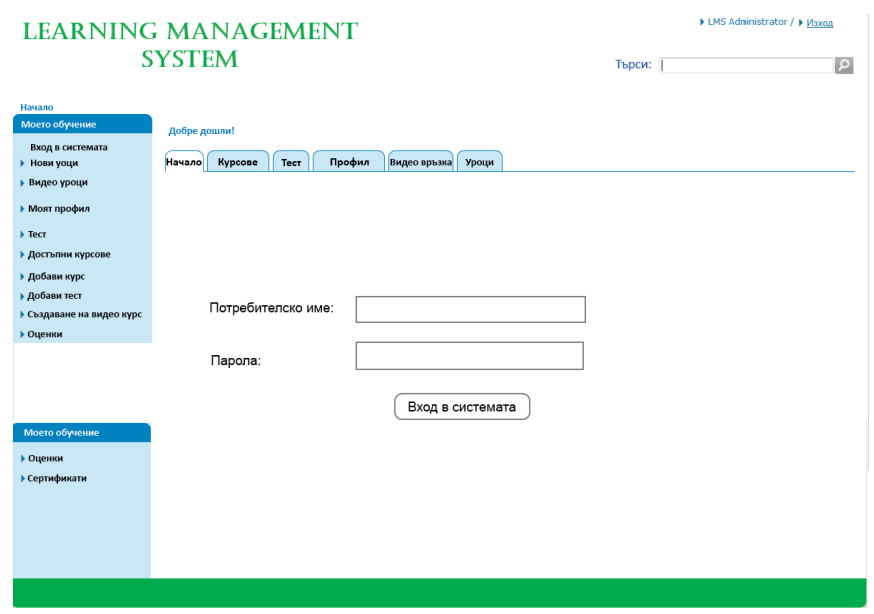

Fig. 1 Example of distance learning system login screen

Reports are generated for time every student spends online and grades from every quiz and exam showed by student or for all students in particular course. Student profile with information about login time, total time online and enrolled courses is presented on Fig. 2. 

SYSTEM

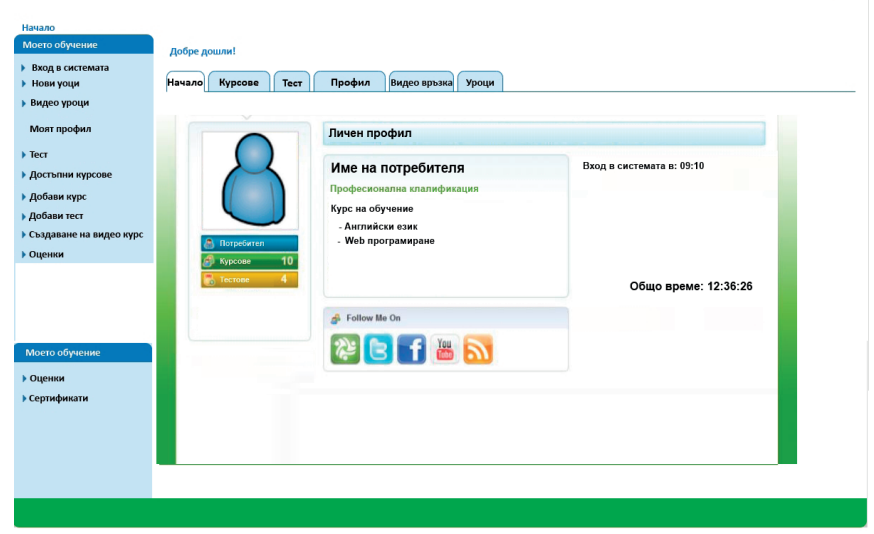

Fig. 2 Example of Student profile screen

However this system does not provide enough interaction between teacher and students. There need to be in person class activities and Q\&A sessions. Also class roster is limited to space in one class room and students must be divided in groups to attend in person lectures.

If a student can't attend to these lectures there is no way to get back in track with other students without going to teacher and take private consultation.

We are trying to overcome this by introducing IPTV services to our existing distance learning system.

\section{ADDING IPTV SERVICES}

To deliver video content over IP network IPTV system needs interactive services. IPTV services can be divided in three main groups: streaming TV, video on demand (VOD) and time-shifted TV. According to ETSI specification [4] Next Generation Networks integrated IPTV include following IPTV services: Broadcast TV; Content on Demand (nCoD, pCoD); Personal Video Recording (cPVR, nPVR); Pay Per View (PPV); Interactive TV (iTV); User Generated Content (UGC); Profiling and personalization; Content Recommendations (CR); Advertising (Ad) and Targeted Advertising (TAI); Messaging services; Notification services; Personalized channel; Bookmarks or Content Marking (CM).

IPTV services provide students with more control over viewed Video channels and give them ability to make decision what Video content to choose and when to watch it. Student can watch IPTV with a number of networkaddressable devices like laptop, personal computer, settop box and TV, smartphone, tablet, gaming consoles, etc. These features make IPTV suitable for our distance learning system.

IPTV can offer new additions to distance learning systems by introducing following services:

- Live video stream

- Video on demand

- Time Shifted TV / Personal video recording
LEARNING MANAGEMENT SYSTEM

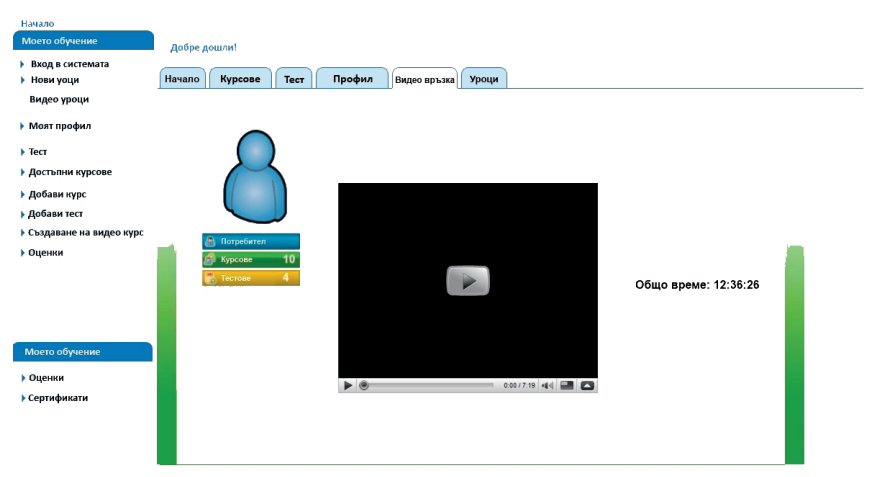

Fig 3. New IPTV services in Distance Learning System

Example for use of each of IPTV services in our distance learning system is shown on Fig. 3 and Table I. Usage of these services is not limited and our system is constantly upgraded with new interactive services for students to use on a daily bases. We get positive feedback from students for added IPTV services.

Table I New services

\begin{tabular}{|c|l|}
\hline IPTV Service & Distance Learning System usage \\
\hline Live video stream & $\begin{array}{l}\text { Live video lessons } \\
\text { Oral exams } \\
\text { Q\&A sessions }\end{array}$ \\
\hline Video on demand & $\begin{array}{l}\text { Video lessons Library } \\
\text { Q\&A Library }\end{array}$ \\
\hline $\begin{array}{l}\text { Time Shifted TV / Per- } \\
\text { sonal video recording }\end{array}$ & $\begin{array}{l}\text { Pause and resume Live sessions } \\
\text { Record live video lessons } \\
\text { Record Q\&A sessions }\end{array}$ \\
\hline
\end{tabular}

\section{CONCLUSION}

As IPTV is transmitted over IP it needs proper compression techniques to compress the video prior to its transmission depending on the available bandwidth. We have found H.264/MPEG-4 AVC compression the best possible solution for this challenge. Now students can watch both live video lessons and video on demand recorded lessons.

Students involved in IPTV distance learning system have a high score of system satisfaction.

\section{FUTURE WORK}

Our vision for future in distance learning systems includes better integration with IPTV and adding features like mobility and portability so students can gain knowledge via smartphone, tablet or any other portable device. Adding more interactive services and improve student interaction with the system.

\section{ACKNOWLEDGMENT}

The present document has been produced with the financial assistance of the European Social Fund under Operational Programme "Human Resources Development". 
The contents of this document are the sole responsibility of "Angel Kanchev" University of Ruse and can under no circumstances be regarded as reflecting the position of the European Union or the Ministry of Education and Science of Republic of Bulgaria.

Project № BG051PO001-3.3.06-0008 “Supporting Academic Development of Scientific Personnel in Engineering and Information Science and Technologies".

\section{REFERENCES}

[1] https://moodle.org/ Feb 2014

[2] O’Driscoll, G., "Next Generation IPTV Services and Technologies", John Wiley \& Sons, Inc, 2008.

[3] Kanev J., Sadinov S., "Analyzing RTSP protocol features for managing video on demand server", UNITECH 2012, Gabrovo Bulgaria, 2012

[4] ETSI TS 182 028: TISPAN NGN Release v.3.5.1: "NGN integrated IPTV subsystem Architecture”, 2011. 